\title{
As Revoltas Liberais de 1842 na perspectiva do historiador Lucio José dos Santos: usos e abusos da memória
}

The Liberal Revolts of 1842 in the perspective of historian Lucio José dos Santos: uses and abuses of memory

Luciana Coelho Gama ${ }^{1}$

Resumo: O presente artigo traz como tema a produção de memória oficial sobre as Revoltas Liberais de 1842, tendo como fonte a conferência sobre o assunto realizada pelo historiador mineiro Lucio José dos Santos em 1942, no âmbito do Instituto Histórico e Geográfico Brasileiro (IHGB). Considerando que Santos era um intelectual conservador, representante da Igreja Católica e da Ação Integralista Brasileira (AIB), o objetivo é relacionar a versão dos fatos por ele construída à influência do contexto institucional em que estava inserido, para compreender a construção de uma memória histórica permeada de elementos conservadores, embora o autor se considerasse "neutro". Para tanto, o conteúdo proferido por Santos na conferência será analisado com base nas premissas de Paul Ricoeur $(1980,2007)$ a respeito dos usos e abusos da memória e das ideologias, em diálogo com os apontamentos de Michel de Certeau (1982) sobre a influência do local de fala do historiador na produção historiográfica.

Palavras-chave: Lucio José dos Santos; Memória; Conservadorismo; Revoltas Liberais de 1842.

Abstract: The theme of this article is the production of the oficial memory about Liberal Revolts of 1842. The historical source used is the conference about the subject made by the historian Lucio José dos Santos, from Minas Gerais. This conference was held in 1942 at the Brazilian Historical and Geographical Institute. Whereas Santos was a conservative intelectual, representative of Catholicism and the conservative political party "Ação Integralista Brasileira", the goal is to relate the version of the facts that he constructed to the influence of the institutional context in which he was inserted. Thus, it may be understand the construction of a historical memory permeated by conservative elements, although the author considered himself as "neutral". The content given by Santos at the conference will be analyzed based on the premises of Paul Ricoeur (1980, 2007) regarding the uses and abuses of memory and ideologies, in dialogue with Michel de Certeau's (1982) notes about the influence of the speech place of the historian in the historiographical production.

Keywords: Lucio José dos Santos; Memory; Conservatism; Liberal Revolts of 1842.

\footnotetext{
${ }^{1}$ Mestre e Doutoranda em História pela Universidade Federal de Mato Grosso (UFMT). Professora na Rede Estadual de Ensino em Mato Grosso.E-mail lu_cgama@yahoo.om.br
} 


\section{LUCIO JOSÉ DOS SANTOS, UM CONSERVADOR CATÓLICO E INTEGRALISTA PRODUZINDO MEMÓRIA NO IHGB}

Lucio José dos Santos (1875-1944) foi um engenheiro, advogado, historiador, político e educador mineiro. Destacou-se ente as décadas de 1920 e 1940 como intelectual conservador e membro do laicato católico: foi diretor do jornal católico O horizonte, fundador do Círculo Operário Católico, da União de Moços Católicos e da Ação Católica da Arquidiocese de Belo Horizonte, tendo sido condecorado pela Santa Sé no pontificado de Pio XI (MELO, 2012, p. 577). Foi ainda fundador do Centro D. Vital de Minas Gerais (MOURÃO, 1959, p. 305). O Centro D. Vital, fundado inicialmente no Rio de Janeiro, na década de 1920, tratava-se de "uma associação de caráter elitista, cujos objetivos mais importantes consistiam em atrair para a Igreja elementos da intelectualidade do país e formar uma "nova geração de intelectuais católicos"” (KORNIS, s/d, p. 01). Já a Ação Católica foi criada em 1935 por Dom Sebastião Leme, em obediência às orientações do Papa Pio XI para que se criassem em todo o mundo associações leigas vinculadas à Igreja Católica (KORNIS, s/d, p. 01). A participação e protagonismo de Lucio dos Santos nessas e em outras associações católicas demonstram sua importância no cenário religioso mineiro e mesmo nacional.

No campo político, fez parte da Ação Integralista Brasileira (AIB), como componente da Câmara dos 40, órgão consultivo de Plínio Salgado, líder do partido que representava uma espécie de fascismo brasileiro. A Câmara dos 40 era formada por 40 homens de "valor moral e intelectual" que se organizavam em comissões especializadas para opinar sobre as questões suscitadas pelo líder. Caso os integralistas chegassem ao poder, o senado do governo seria formado pela Câmara dos 40 (TRINDADE, 1979, p. 173-174).

Santos foi ainda integrante do Clube Floriano Peixoto, do Instituto Histórico e Geográfico de Minas Gerais (IHGMG) (GAMA, 2016, p. 63-65), sócio correspondente do Instituto Histórico e Geográfico Brasileiro (IHGB) (RIHGB, 1943, p. 117), membro da Sociedade Mineira de Engenheiros, da Academia Mineira de Letras e da Academia de Ciências de Minas Gerais (MELO, 2012, p. 576-577). Lecionou na 
Escola de Minas de Ouro Preto e na Universidade de Minas Gerais (UMG), ocupando o cargo de reitor entre 1931 e 1933. Foi ainda Diretor de Instrução Pública do Estado de Minas Gerais entre 1924 e 1927 (MELO, 2012, p. 576).

Em 21 de agosto de 1942, por ocasião do centenário das Revoltas Liberais de 1842, Santos proferiu na sede do IHGB uma conferência sobre o assunto, intitulada A Revolução de 1842 em Minas Gerais, posteriormente publicada na Revista do Instituto Histórico e Geográfico Brasileiro (RIHGB). As Revoltas Liberais de 1842 foram levantes ocorridos em São Paulo, Rio de Janeiro e Minas Gerais, com o objetivo de levar o Partido Liberal de volta ao poder. Após o período regencial e com a manobra política que decretou a maioridade de Dom Pedro II ainda com 14 anos, em 1840, o Imperador conduziu ao poder o grupo liberal, que havia apoiado a antecipação de sua maioridade. No entanto, após o agravamento da Guerra dos Farrapos no sul do país, as pressões da Inglaterra pela extinção do tráfico negreiro e a violência que permeou o processo eleitoral, D. Pedro II terminou por dissolver a câmara liberal recém-eleita. Em 1841 um novo ministério foi formado com membros do Partido Conservador, que começaram a reverter as políticas implantadas pelos liberais desde o período regencial. A situação levou os liberais ao conflito armado em 1842, em resistência às reformas conservadoras (CARNEIRO, 2016, p. 287).

Em Minas Gerais, o conflito ocorreu na cidade de Barbacena, em 10 de junho de 1842. Lucio dos Santos, em sua conferência, aborda o tema de forma factual, mas também emite uma série de juízos de valor a respeito da sedição, do contexto em que ocorreu e se suas consequências, num exercício de construção da memória oficial sobre o tema com base em sua própria perspectiva, com a legitimação do IHGB.

Na obra A memória, a história, o esquecimento (2007), o filósofo Paul Ricoeur apresenta reflexões profundas e pertinentes sobre a memória e sua relação com a ciência histórica. As análises partem das discussões dos filósofos gregos, que entendiam a memória como imagem-afecção do passado se manifestando no presente; passam pela compreensão da memória em si mesma por meio da análise fenomenológica husserliana, pelo debate dos usos e abusos da memória individual e coletiva, a necessidade e o direito ao esquecimento e as condições e possibilidades para o perdão. Em relação à História, as reflexões giram em torno da memória como mero objeto da ciência histórica ou como condição essencial para sua existência, além de 
questionamentos sobre o papel da historiografia na preservação da memória ou no engessamento e descaracterização da mesma.

No presente estudo, temos o objetivo de identificar e analisar os usos e abusos da memória sobre as Revoltas Liberais de 1842 na historiografia oficial produzida pelo IHGB, tendo como fonte a conferência realizada por Lucio José dos Santos. O historiador parte da análise do evento em Minas Gerais, sua terra natal, mas termina por analisar também o contexto nacional em que ocorreu, além das consequências. Sua visão dos fatos é claramente pautada pela conjuntura institucional, política e religiosa em que estava inserido, influenciando a elaboração de sua narrativa e a construção da memória oficial corroborada pelo Instituto Histórico. Para compreender a relação entre o lugar de fala do historiador e sua produção, utilizaremos os preceitos de Michel de Certeau em A escrita da História (1982), De acordo com o teórico,

"toda pesquisa historiográfica se articula com um lugar de produção socioeconômico, político e cultural. Implica um meio de elaboração circunscrito por determinações próprias: uma profissão liberal, um posto de observação ou de ensino, uma categoria de letrados, etc. Ela está, pois, submetida a imposições, ligada a privilégios, enraizada em uma particularidade. É em função deste lugar que se instauram os métodos, que se delineia uma topografia de interesses, que os documentos e as questões, que lhes serão propostas, se organizam (CERTEAU, 1982, p. 66).

Compreendemos que Lucio dos Santos, embora tivesse a pretensão de produzir uma versão "neutra" dos fatos, certamente estava imbuído por ideais conservadores católicos e integralistas, que contextualizaram suas pesquisas históricas e permearam a apresentação dos resultados, inclusive a conferência proferida no IHGB em 1942.

Sobre os usos e abusos da memória, Ricoeur dedica um capítulo inteiro de sua obra. $\mathrm{O}$ autor afirma que a memória é exercitada, não se limitando apenas à lembrança que nos surge, mas à recordação que buscamos. Dessa forma, cada indivíduo "faz" memória, assim como o historiador "faz" história. O "fazer" memória é o exercício da recordação, o seu uso. Os usos da memória também estão sujeitos aos abusos, sobretudo quando há manipulação em nome de ideologias (RICOEUR, 2007, p. 171-174). O historiador, ao consultar os documentos, que são as memórias e testemunhos escritos e arquivados, reconstrói o passado pelas lentes do presente, forjando a memória sobre o objeto abordado sob seu próprio viés interpretativo. A 
projeto de verdade da História está atrelado aos limites desse espaço de validação, entre o envolvimento pessoal e o social (mais especificamente institucional) do historiador (RICOEUR, 2007, p. 347-348). Nesse sentido, Ricoeur concorda com Certeau, considerando que "relacionar um produto a um lugar constitui [...] a primeira tarefa de uma epistemologia do conhecimento histórico” (RICOEUR, 2007. p. 177).

Segundo Ricoeur, a memória prática pode ser instrumentalizada pelos detentores do poder, que promovem excessos de memória em relação a determinados fatos históricos e excessos de esquecimento em relação a outros (RICOEUR, 2007, p. 93-94). A memória manipulada interfere na formação de identidades, podendo ser utilizada para a legitimação de ideologias. Ainda de acordo com o teórico, o fenômeno ideológico "está ligado à necessidade que tem um grupo social de se dar a si mesmo uma imagem de si próprio, de se representar, no sentido teatral da palavra de se pôr em jogo e em cena” (RICOEUR, 1980, p. 24). A ideologia não é, portanto, algo necessariamente ruim. Embora seja utilizada para legitimar o domínio de determinados grupos sobre outros, a ideologia abarca o fenômeno mais amplo da integração social, sendo a dominação um aspecto desse fenômeno, porém não o único (RICOEUR, 1980, p. 22). Todos os indivíduos pertencem "a uma história, uma classe, uma nação, a uma cultura, a uma ou várias tradições" (RICOEUR, 1980, p. 41), e todo esse contexto nos precede e nos permeia, portanto não somos capazes de ser neutros e não ideológicos:

Ao assumir essa pertinência que nos precede e nos carrega, assumimos também o primeiro papel da ideologia, descrito acima como função mediadora da imagem, da representação de si; e, pela função mediadora das ideologias, participamos igualmente das suas outras funções, de dissimulação e de distorção. Agora já sabemos, porém, que a condição ontológica da pré-compreensão exclui qualquer reflexão total que nos colocaria na condição privilegiada do saber nãoideológico. (RICOEUR, 1980, p. 41)

A formação identitária das sociedades e a forma com que os grupos sociais se enxergam e interpretam suas comunidades se dão por meio da ideologia e da construção da memória. O IHGB é simbólico neste sentido, pois foi criado ainda no período monárquico ${ }^{2}$ com o objetivo de construir a memória e a identidade nacionais

\footnotetext{
${ }^{2}$ O IHGB foi criado em 1838, tendo suas bases lançadas pelo militar Raimundo José da Cunha Matos e o cônego Januário Barbosa, com 27 membros em sua lista de fundadores, a maioria funcionários públicos. O objetivo da instituição era sistematizar uma identidade nacional própria para o Brasil, consolidando a
} 
pautadas nos ideais monarquistas, adaptando-se paulatinamente às ideologias republicanas após a Proclamação, sobretudo a partir de 1908, quando o Barão do Rio Branco assumiu a presidência da agremiação (GUIMARÃES, 2007, p. 29-30). Lucio dos Santos tornou-se sócio do $\mathrm{IHGMG}^{3}$ e do IHGB já no período republicano, sendo responsável por importantes trabalhos legitimadores da República, tais como $A$ Inconfidência Mineira - papel de Tiradentes na Inconfidência Mineira (1927), obra realizada sob encomenda do IHGB, e que consolidou na historiografia brasileira a imagem de Tiradentes como herói nacional (GAMA, 2016).

\section{A CONFERÊNCIA- VISÃO DO AUTOR SOBRE AS REVOLTAS LIBERAIS DE} 1842

Em sua conferência sobre as Revoltas Liberais, Santos inicia descrevendo a situação da cidade de Barbacena em 10 de junho de 1842, data em que irrompeu o levante, que durou 72 dias em Minas Gerais. O historiador fala sobre os vários chefes da revolta, o ambiente em Barbacena no período, o governo conservador e a tomada de poder pelos liberais, frisando que a revolta não era contra o Imperador Dom Pedro II, mas contra os conservadores, a quem os liberais acusavam de estar coagindo o "adorado monarca", comprometendo o trono e a liberdade nacionais e traindo os interesses do país. A revolta era esperada em Minas Gerais, visto que o Rio de Janeiro já havia feito proclamações subversivas, a Revolução Farroupilha corria há sete anos no Rio Grande do Sul e desde o dia 17 de maio São Paulo agitava-se com a revolta dos liberais. Todos esses levantes serviam como pretexto para que insatisfeitos de toda ordem se aproveitassem, inclusive desejando mais que uma simples mudança de ministérios (SANTOS, 1943, p. 118).

Santos frisa que, apesar da intenção de articulação entre os levantes de São Paulo e Minas Gerais, os planos foram frustrados pela rápida resposta da guarda

centralização do Estado pela ordem monárquica e viabilizando a integração das regiões do país (GUIMARÃES, 1988, p. 8-10).

${ }^{3}$ O IHGMG foi fundado em 16 de junho de 1907, na Câmara dos Deputados do Congresso Mineiro, em Belo Horizonte, por letrados que concretizaram o projeto iniciado na agremiação republicana Clube Floriano Peixoto, fundada também em Belo Horizonte em 1898 (GONÇALVES e NICOLAZZI, 2014, p. 93). Lucio dos Santos foi integrante do Clube Floriano Peixoto, portanto provavelmente integrou o IHGMG desde a sua fundação. 
nacional. Prossegue o letrado falando sobre o manifesto lançado pelos liberais com os motivos que os levaram à revolta. A alegação era que os conservadores cerceavam as liberdades individuais da população, prendiam pessoas inocentes, perseguiam a imprensa e impediam o Imperador de ouvir as demandas da oposição (SANTOS, 1943, p. 119- 120). O manifesto dos liberais de Minas Gerais protestava ainda contra as influências estrangeiras no Brasil, exaltando a coragem dos paulistas por defenderem heroicamente as liberdades públicas e a Constituição e conclamando os mineiros a ajudá-los. A província de Minas Gerais se dividiu, com parte das Câmaras Municipais apoiando o governo revolucionário e parte defendendo o retorno do governo conservador. O Imperador se manifestou em favor da legalidade e contra os revoltosos (SANTOS, 1943, p. 121-122).

Após a descrição dos acontecimentos, Lucio dos Santos emite sua primeira opinião sobre os levantes de 1842. Diz o historiador:

Mas, até onde tinham razão os que se levantaram contra o govêrno legal, há um século?

Não será possível defender o poder sem lançar a maldição sôbre os que tentaram derribá-lo, e nem mesmo descobrir algo de generoso e nobre naqueles que assim se sacrificaram e foram vencidos?

De outro lado, não será lícito engrandecer e saudar a memória dos sacrificados voluntários de 1842 , sem pronunciar o anátema sôbre o govêrno que dirigia os destinos de nossa pátria, em épocas tão tormentosas?

Não será possível que tivessem ambos razão?

Mas, nesse caso, que fatalidade foi aquela, que lançou uns contra os outros homens, que se deveriam entender, porque uns e outros só tinham em vista a felicidade de sua pátria, felicidade que todos só julgavam possível sob os auspícios da monarquia constitucional representativa entregue à dinastia de Bragança?

Questões são essas que, hoje, a um século de distância, dissipados os ódios que turvaram a vista de nossos antepassados, nós podemos debater e resolver serenamente, para chegarmos, tanto quanto possível à fraqueza humana, ao conhecimento da verdade (SANTOS, 1943, p. 122).

Como representante do IHGMG e do IHGB, instituições interligadas que tinham por premissa construir a historiografia oficial regional, no caso do primeiro, e nacional, no caso do segundo, Lucio dos Santos buscava resgatar a "verdade" dos fatos e acreditava que, por meio da pesquisa documental e do afastamento temporal, poderia fazer uma análise neutra doas revoltas liberais 
Nesse sentido, Santos discorre a respeito da importância dos documentos históricos, mas também da função do historiador enquanto intérprete e crítico das fontes. $\mathrm{O}$ intelectual ressalta que seu objetivo na conferência não é fazer um relato factual da revolta em Minas Gerais desde seu irromper até o desfecho com a derrota dos liberais, pouco mais de dois meses depois (SANTOS, 1943, p. 123), mas interpretar os acontecimentos. Elenca uma série de obras que narravam os fatos em detalhes, algumas produzidas logo após as revoltas por participantes ou testemunhas, o que lhes comprometeria a imparcialidade, mas não o valor histórico, afinal eram fundamentais para as pesquisas posteriores. Santos acredita que a fórmula para descobrir a verdade é fazer uma análise distanciada da documentação, levando em conta os pontos de vista de revoltosos e legalistas:

Sôbre todo esse acervo de elementos é que se vai exercer a crítica quando a distância dos acontecimentos, o restabelecimento da paz, o apaziguamento das lutas, o esquecimento dos ódios partidários a permitirem justa, serena, esclarecida, imparcial (SANTOS, 1943, p. 126).

Após fazer essas considerações sobre a almejada neutralidade na pesquisa histórica, Santos tece apontamentos sobre a importância de se conhecer o passado, pois segundo seu entendimento, as lembranças tanto são motivo de orgulho pelas glórias do país, quanto podem servir para lembrar ao povo das desgraças e dar estímulo ao reerguimento nacional, quando necessário (SANTOS, 1943, p. 129). Para o letrado, um povo sem história é um povo sem cultura, e "é pela memória, pela História e pela tradição, que se traduz e mantém a continuidade na vida de um povo sem a qual não é possível um progresso cultural verdadeiro" (SANTOS, 1943, p. 130). Prossegue o autor criticando o relativismo e afirmando que os valores morais não são variáveis de acordo com a época e a sociedade, mas sim imutáveis e devem ser baseados no cristianismo, único detentor das verdades universais (SANTOS, 1943, p. 132).

Percebe-se que a interpretação do autor sobre a busca de verdade pela História e a importância da manutenção da memória está permeada por suas próprias perspectivas cristãs. Na condição de católico atuante, Santos acredita que as bases sólidas da "verdade" e do "progresso" das sociedades devem estar assentadas na moral do cristianismo, e aproveita a apresentação de sua pesquisa histórica no IHGB para defender seus pontos de vista. Certamente o Instituto corroborava essa visão, ou ao 
menos não se posicionava contrário a ela, tendo em vista a aceitação e publicação integral da conferência na revista oficial da instituição.

Em um parêntese na narrativa sobre as Revoltas Liberais, Santos continua sua defesa dos princípios cristãos mencionando povos africanos "primitivos" que, apesar da cultura "simples, rudimentar e grosseira", eram monoteístas e monogâmicos, o que para o autor desmentia os postulados da teoria evolucionista e comprovava a universalidade das ideias morais que a doutrina cristã apenas teria aperfeiçoado (SANTOS, 1943, p. 133). A análise desses "ideais universais", segundo Santos, serviria para demonstrar que há pontos de referência invariáveis que servem para dar sentido à História e que o exame do passado deve "deduzir lições e ensinamentos para o futuro" (SANTOS, 1943, p. 134), mas que sua função, assim como a do IHGB, não era julgar os revoltosos do passado, mas compreender e homenageá-los por, ao seu modo, terem se sacrificado em nome da pátria.

Seguindo a conferência, Lucio dos Santos faz reflexões sobre a Independência do Brasil, que considera ter ocorrido da forma correta, sob o signo da monarquia, o que teria evitado a fragmentação do território nacional e o destino de “ditaduras e anarquias" que afetavam os outros países da América Latina (SANTOS, 1943, p. 134-135). Essa interpretação é coerente com os posicionamentos do IHGB, que apesar de estar totalmente adaptado à República, construía positivamente a memória sobre o período monárquico e a família real, afinal Dom Pedro II foi o principal incentivador do grêmio, financiando-o por décadas (GUIMARÃES, 1988, p. 9).

Ainda abordando a Independência do Brasil, o historiador elogia as intenções de D. Pedro I, mas afirma que o governo se caracterizou pelos conflitos entre seu próprio absolutismo e os arroubos liberais da população. Aqui, Santos faz críticas à ideologia liberal:

Como reação contra o regime absoluto então dominante, produziu nos primeiros momentos o liberalismo muitos resultados brilhantes. Era, porém, intrinsecamente mau; e assim, quando poude impregnar as novas instituições políticas e sobretudo fermentar na ordem econômica, veio a produzir todos os males que aí estão a culminar na gravíssima situação que o mundo atravessa. Muito poucos se encontrarão hoje, que acreditem ainda nas belezas do Estado liberal meramente jurídico, simples juiz e polícia, embalados na vã expectativa de que, em tôdas as ordens de manifestações da atividade humana, se possam harmonizar as cousas por si mesmas, pelo jôgo espontâneo de fôrças naturais e fatais, assim como no firmamento se equilibram e harmonizam os astros pelo simples jôgo da atração e da força centrífuga. Pelo menos nós, no Brasil de hoje, em tal não acreditamos (SANTOS, 1943, p. 135). 
Nesse ponto o autor expõe claramente sua perspectiva integralista. O Integralismo era uma ideologia fascista adaptada ao contexto brasileiro, de forte cunho nacionalista, espiritualista, anticomunista e antiliberal (TRINDADE, 1979, p. 279). Aproveitando o tema da conferência, Santos insere apontamentos e opiniões suas sobre o liberalismo, criticando a ideologia que, segundo ele, começou com boas intenções (conter os abusos do absolutismo) e acabou se tornando um sistema fraco, incapaz de resolver os problemas políticos, econômicos e sociais que surgiam quando não havia controle das atividades humanas. $\mathrm{O}$ autor assevera que os brasileiros, naquele momento, não confiavam nas prerrogativas liberais, demonstrando que, mesmo após o fim da AIB, ocorrido em 1937, continuava eivado pelos ideais do partido e acreditava que eram os melhores para o país.

Santos continua suas reflexões afirmando que o primeiro reinado no Brasil se caracterizou pelo embate entre as "ideias sem forma" dos grupos liberais e as "formas sem ideias", dos absolutistas. Reiterando seus posicionamentos católicos, argumenta que o campo das ideias precisa ser norteado pela religião, "pelos mandamentos" e pelas tradições e "desígnios de Deus", pois do contrário tornam-se subversivas e destrutivas, como havia ocorrido com os liberais, os quais, segundo o autor, converteram suas ideias sem forma em chavões revolucionários inócuos, ao passo que os absolutistas se mantinham arraigados a formas de organização que não se encaixavam mais ao ideário político da época (SANTOS, 1943, p. 137-138). A rivalidade gerou a crise que culminou com a abdicação de D. Pedro I, que Santos aponta como vitória dos liberais, mas que quase deitou a perder todo o sistema monárquico (SANTOS, 1943, p. 139). Após, os liberais acabam se dividindo em exaltados, moderados e restauradores, com os dois primeiros grupos dando origem ao Partido Liberal e ao Partido Conservador, ambos com ideologias diferentes, mas práticas semelhantes (SANTOS, 1943, p. 140).

O autor segue relatando as manobras políticas para que D. Pedro II fosse declarado maior de idade, consideradas por ele ilegais. Os liberais eram os mais interessados na manobra, enquanto o líder dos conservadores era contrário (SANTOS, 1943, p. 142). Apesar de ter afirmado que liberais e conservadores eram parecidos em suas práticas, Santos não esconde sua preferência pelo segundo grupo, que de acordo com ele desejava manter as conquistas já estabelecidas, sem deixar irromper a "anarquia" (SANTOS, 1943, p. 141). Os liberais venceram em condições suspeitas as eleições para a câmara legislativa que atuaria entre 1842 e 1845, e em 1841 acabaram 
sendo substituídos nos ministérios pelos conservadores, mas decidiram que, quando a câmara assumisse, acusaria os ministros de tomarem resoluções inconstitucionais. De fato a câmara recém empossada fez acusações, mas os ministros solicitaram ao monarca que a mesma fosse dissolvida, sendo atendidos. Esse foi o estopim para as revoltas liberais (SANTOS, 1943, p. 145).

Após fazer essas considerações sobre a transição do primeiro para o segundo reinado e as causas das revoltas liberais, Santos passa a narrar os fatos ocorridos em Minas Gerais, com a tomada dos revoltosos de Barbacena e várias outras cidades e a contraofensiva legalista, que saiu vitoriosa. Utiliza como fonte a obra do cônego José Antônio Marinho, membro do Partido Liberal e contemporâneo aos acontecimentos. Santos pontua que, no seu entendimento, a visão de Marinho era deturpada por sua posição política, não enxergando os erros cometidos pelos liberais e atribuindo a derrota à suposta falta de liderança dos revoltosos. Além disso, Marinho teria sido injusto com líderes conservadores que demonstraram clemência aos derrotados (SANTOS, 1943, p. 157).

Santos enaltece o Cel. José Feliciano da Cunha, o governador interino proclamado pelos liberais durante a revolta, dizendo que ele foi um homem moderado e conciliador, alçado involuntariamente à condição de líder do motim (SANTOS, 1943, p. 161-162). Por fim, inicia a conclusão do pronunciamento alegando que, sob seu ponto de vista, os liberais foram contraditórios ao se revoltarem conta a dissolução da câmara, tendo em vista que essa era uma prerrogativa constitucional do Imperador. Além disso, as medidas tomadas pelos conservadores ao assumirem os ministérios teriam sido boas para o país, o que levantava sobre os liberais a suspeita de apenas estarem buscando um falso pretexto para a revolta. Pontua o autor ainda que os liberais lutaram pela antecipação da maioridade do Imperador, mas depois julgavam que o Conselho de Estado o estaria influenciando negativamente: "porque supô-lo agora capaz de deixar-se dominar pelo Conselho de Estado, em vez de apenas se aproveitar da experiência, que lhe faltava ainda e que era de presumir em homens velhos, dedicados servidores do país?” (SANTOS, 1943, p. 163).

Continuando suas conclusões, Lucio dos Santos acusa os liberais de terem derrubado D. Pedro I para depois derrubarem a Regência, dando o golpe da maioridade. No entanto, ao se assenhorarem do governo no segundo reinado, iniciaram vinganças partidárias e depois recorreram às armas para impedir que o Imperador exercesse seus 
direitos legais de sancionar leis e dissolver uma "Assembleia facciosa". "Onde ficou o liberalismo?", questiona o historiador (SANTOS, 1943, p. 164). O próprio responde:

É que o liberalismo é uma arma de oposição e não um instrumento de govêrno. Quando na oposição, cada um dos dois partidos existentes, liberal e conservador, reclamava normas e invocava princípios de que se esquecia uma vez no poder. Chegado ao poder, cada partido, em regra, procurava manter-se e consolidar-se mediante os mesmos processos que combatera quando fora dêle (SANTOS, 1943, p. 164).

Prossegue o autor afirmando que o Partido Liberal errou ao fomentar a

revolta:

Pensamos, pois que não assiste razão aos liberais no se rebelarem contra o poder legítimo. Se, a seu trono, desmandavam no poder os conservadores, não faziam mais que revidar as represálias de que haviam sido vítimas; e aos liberais faltava pelo menos a fôrça moral para se erguerem como os restauradores das verdadeiras normas de govêrno. E assim foi felicidade o não ter vingado a revolução (SANTOS, 1943, p. 164).

Para finalizar a conferência, Santos volta a atenuar o discurso sobre os liberais, como fizera no início do pronunciamento. Assevera que, apesar do "julgamento histórico" ser contrário aos revoltosos de 1842, os chefes do movimento eram em sua maioria homens valorosos, tendo se mostrado desinteressados e dignos durante o conflito. Os liberais erraram, mas os conservadores também cometiam erros (SANTOS, 1943, p. 165). Na opinião do autor, os fatos históricos anteriores e posteriores às revoltas de 1842 demonstram que os liberais não eram coerentes com o próprio liberalismo e, embora dissessem estar defendendo o Imperador, na realidade não aceitaram que o mesmo aplicasse seus direitos constitucionais. Dessa forma, a História (e não ele próprio) julgava que os liberais erraram ao fazerem os levantes armados.

A análise da conferência proferida por Lucio José dos Santos no Instituto Histórico e Geográfico brasileiro em 1942 e publicada na Revista do Instituto no ano posterior é bastante elucidativa do tipo de memória que tanto o historiador conferencista quanto o IHGB desejavam construir a respeito dos levantes liberais de 1842. Compreendendo que Santos estava envolvido com instituições conservadoras no campo religioso e político, as visões católica e integralista entremeiam seu pronunciamento e a memória por ele sobre os levantes liberais. 
Embora o intelectual se considere "neutro" por estar analisando o assunto com distância temporal, tendo a pretensão de fazer uma análise isenta e sem julgar os liberais ou os conservadores, acaba emitindo juízos negativos sobre os liberais, acusando-os de incoerência. Essa interpretação é pertinente à ideologia integralista, professada por Santos até sua morte (SILVA, 1947, p. 07). A AIB posicionava-se contra o liberalismo, pois acreditava que as desigualdades promovidas pela ideologia levariam o povo a se revoltar e aderir ao socialismo. Para os integralistas, o liberalismo garantiria liberdade somente aos mais fortes, que tivessem poder econômico o suficiente para assegurar os próprios direitos (TRINDADE, 1979, p. 228). Dessa forma, Santos critica aquilo que considera desordens provocadas pelos liberais, dizendo que eles não tinham força moral e que não respeitaram a ordem constitucional, embora se julgassem defensores dela. Além disso, o liberalismo seria o causador de muitas desordens pelo mundo afora, pois pretendia que as sociedades se organizassem e harmonizassem naturalmente, sem intervenções, o que seria impossível. O liberalismo seria, portanto, "intrinsecamente mau", um conjunto de "ideias sem forma". A solução apontada pelo autor também é influenciada pelas concepções institucionais: seria a moral cristã, única maneira pela qual as sociedades poderiam se organizar, chegando ao verdadeiro "progresso cultural".

\section{A CONSTRUÇÃO DA MEMÓRIA OFICIAL E O CONTEXTO INSTITUCIONAL DO HISTORIADOR}

Conforme já citado neste trabalho, Paul Ricoeur aponta que a memória desde a Grécia antiga pode ser compreendida como imagem-afecção, que fica impressa e se manifesta como rastro do passado no presente, podendo tanto ser buscada ativamente (recordação) como surgir de forma espontânea e passiva (evocação simples) (RICOEUR, 2007, p. 27-39). A preocupação do filósofo é abordar as questões da experiência temporal e da operação narrativa e suas relações com a memória e o esquecimento, bem como os problemas do vínculo da memória com a história. Nesse sentido, Ricoeur almeja a construção de uma política justa da memória, compreendendo que há abusos nos usos da memória e do esquecimento:

“ [...] perturba-me o inquietante espetáculo que apresentam o excesso de memória aqui, o excesso de esquecimento acolá, sem falar da 
influência das comemorações e dos erros de memória - e de esquecimento. A ideia de uma política justa de memória é, sob esse aspecto, um de meus temas cívicos confessos" (RICOEUR, 2007, p. 17).

Em sua relação com a História, a memória constitui-se tanto como objeto da ciência histórica como condição sem a qual essa ciência não pode existir, sendo a História apenas um meio pelo qual a memória se revela (RICOEUR, 2007, p. 397-401). De qualquer forma, o conceito de memória é importante para a compreensão da historiografia, pois os historiadores utilizam a memória em suas pesquisas (no caso de Lucio dos Santos, a memória presente em testemunhos documentados do período) e também são construtores de memória, sobretudo memórias oficiais, como no caso dos historiadores do IHGB.

Lucio José dos Santos, como sócio correspondente do IHGB, foi chamado a proferir conferência sobre as Revoltas Liberais de 1842, cem anos após a ocorrência do fato. A data é simbólica e a preocupação do Instituto em levar um historiador mineiro para abordar o tema demonstra intenção em forjar a memória oficial sobre o tema, partindo de seus desdobramentos em Minas Gerais e produzindo uma análise do que seriam as consequências em âmbito nacional caso os liberais vencessem.

Certamente a interpretação pessoal do historiador permeia suas análises, mesmo que ele as considerasse imparciais. Lucio dos Santos fala não apenas como sócio do IHGB, mas como integrante de movimentos católicos de relevância e partidário da Ação Integralista Brasileira, sendo um dos membros do conselho de Plínio Salgado. Seu local de fala é determinante para a abordagem que constrói sobre os levantes liberais. Michel de Certeau nos chama atenção para esse aspecto, pois o meio institucional a que o historiador está atrelado é fundamental para compreender sua produção. O local de fala é um mobilizador direto do tipo de pesquisa realizado e dos interesses a serem contemplados (CERTEAU, 1982, p. 41), pois o historiador representa as organizações e também é influenciado por elas ideologicamente, o que se reflete em sua produção.

Na conferência A Revolução de 1842 em Minas Gerais, evidencia-se a influência do ideário integralista nos vários momentos em que o autor critica o liberalismo, além das concepções católicas de exaltação da moral cristã como norteadora das nações em busca de "civilização e progresso". Santos aproveita a oportunidade de conferenciar no âmbito do IHGB para inserir sua visão conservadora 
católica/integralista à fala, criticando fortemente o liberalismo, embora afirmasse que os liberais tinham boas intenções. Esse ponto é contraditório, mas percebe-se que Santos se preocupou em criticar a ideologia liberal como um todo e as ações dos liberais nos dois reinados brasileiros, porém sem atribuir culpas a indivíduos específicos. Ao contrário, o intelectual exalta alguns líderes liberais, dizendo que procuraram agir com moderação, além de dizer que os conservadores também erraram, embora as críticas a esse grupo sejam bem menos duras que aos liberais. Compreendemos que a exposição sobre as revoltas de 1842 foi utilizada pelo autor para emitir juízos comuns ao catolicismo e ao integralismo, que apesar de divergirem em alguns aspectos, tinham uma série de pontos em comum, entre eles o profundo anticomunismo e antiliberalismo, que aproximavam fortemente as duas entidades (AMADO, 2018, p.1) sendo Lucio dos Santos um dos representantes dessa aproximação.

Concluímos, a partir do exame da conferência proferida por Lucio José dos Santos, que o IHGB corroborou a construção de memória conservadora sobre os levantes liberais de 1842 feita pelo intelectual católico/integralista. Trata-se de um exemplo da memória manipulada ideologicamente, embora não se assuma como tal. Conforme Paul Ricoeur, os processos ideológicos não se reconhecem, prevalecendo a tendência de apontar a ideologia no outro (RICOEUR, 2007, p. 95), como Santos faz ao apontar incongruências na obra do José Antônio Marinho, exatamente por esta estar influenciada pelo ideário liberal. Certamente o trabalho de Lucio José dos Santos tem valor historiográfico, pois o intelectual se preocupou em levantar fontes documentais de variados historiadores e testemunhas dos fatos. Entretanto, sabemos não ser possível a neutralidade que o intelectual alegou ter obtido, afinal a produção historiográfica e construção de memórias oficiais estão sempre permeadas pela visão do historiador, normalmente atrelada às instituições em que está inserido e perpassada pelas ideologias que defende.

\section{FONTE}

SANTOS, Lucio José dos. A Revolução de 1842 em Minas Gerais (conferência). Revista do instituto histórico e geográfico brasileiro (RIHGB), vol. 180. Rio de Janeiro: Imprensa Nacional, 1943. 


\section{REFERÊNCIAS BIBLIOGRÁFICAS}

AMADO, Thiago da Costa. Para a Glória de Deus e da Nação - O Integralismo, a Igreja Católica e o Laicato no Brasil dos anos 1930. Curitiba: Editora Prismas, 2018.

CARNEIRO, André Rocha. A Revolta Liberal de 1842 em um município do Vale do Paraíba Fluminense - Barra Mansa. Revista Maracanan, Rio de Janeiro, n. 15, p. 285298, jul/dez. 2016.

CERTEAU, Michel de. A escrita da História. Rio de Janeiro: Forense Universitária, 1982

GAMA, Luciana Coelho. As vestimentas do mártir: as representações sobre Tiradentes em Joaquim Norberto de Souza Silva e Lucio José dos Santos e a narrativa da Nação no discurso didático. Dissertação (Mestrado em História) - Instituto de Ciências Humanas e Sociais, Universidade Federal de Mato Grosso, Cuiabá, 2016.

GONÇALVES, Tatiana Mol; NICOLAZZI, Fernando. Inventando a historiografia mineira: o Instituto Histórico e Geográfico de Minas Gerais em sua "primeira fase", 1907-1927. Revista de Teoria da História, Goiânia, ano 6, n. 11, p. 93-109, maio. 2014.

GUIMARÃES, Lúcia Maria Paschoal. Da Escola Palatina ao Silogeu: Instituto Histórico e Geográfico Brasileiro (1889-1938). Rio de Janeiro: Editora Museu da República, 2007.

GUIMARÃES, Manoel Luís Salgado. Nação e civilização nos trópicos: O Instituto Histórico e Geográfico Brasileiro e o Projeto de uma História Nacional. Estudos Históricos, Rio de Janeiro, n. 1, p. 5-27, 1988.

KORNIS, Mônica. Ação Católica (verbete). Centro de Pesquisa e Documentação de História Contemporânea do Brasil (CPDOC), Fundação Getúlio Vargas, s/d. Disponível em: <http://www.fgv.br/cpdoc/acervo/dicionarios/verbete-tematico/acaocatolica-brasileira-acb>, acesso em 06/01/2019. 
KORNIS, Mônica. Centro Dom Vital (verbete). Centro de Pesquisa e Documentação de História Contemporânea do Brasil (CPDOC), Fundação Getúlio Vargas, s/d. Disponível

em: $<$ https://cpdoc.fgv.br/sites/default/files/verbetes/primeirarepublica/CENTRO\%20D OM\%20VITAL.pdf>, acesso em 06/01/2019.

MELO, Cleide Maria Maciel de. "Missão Universitária": Relatos de viagem de Lúcio José dos Santos - Brasil/Minas Gerais/1930. Formación de Élites y educación superior en Iberoamérica (SS. XVI-XXI), Salamanca, v. 1, p. 575-679, 2012.

MOURÃO, Paulo Krüger Corrêa. Dr. Lucio José dos Santos. Revista do Instituto Histórico e Geográfico de Minas Gerais, Belo Horizonte, v. VI, p. 299-306, 1959.

REVISTA DO INSTITUTO HISTÓRICO E GEOGRÁFICO BRASILEIRO (RIHGB), vol. 180. Rio de Janeiro: Imprensa Nacional, 1943.

RICOEUR, Paul. A memória, a história, o esquecimento. Campinas: Editora da Unicamp, 2007.

RICOEUR, Paul. Ciência e Ideologia. Cadernos de História e Filosofia da Ciência, Campinas, v. 1, série 1, p. 21-43, 1980.

SILVA, Jayme Ferreira da. A verdade sobre o Integralismo. Rio de Janeiro: Imprensa Nacional, 1947.

TRINDADE, Hélgio. Integralismo - o fascismo brasileiro na década de 30. São Paulo: DIFEL, 1979. 